\title{
Myocardial bridge
}

\author{
M. Tiryakioglu', M.N. Aliyu ${ }^{2}$ \\ ${ }^{1}$ Department of Anatomy, Faculty of Medicine, Near East University, Nicosia, Cyprus \\ ${ }^{2}$ Department of Human Anatomy, Faculty of Basic Sciences, Yusuf Maitama Sule University, Kano, Nigeria
}

[Received: 29 May 2019; Accepted: 7 July 2019]

Myocardial bridging (MB) is an anatomical variant in which an epicardial coronary artery passes under a bridge of myocardium. The most commonly affected vessel is the left anterior descending coronary artery, although other branches such as the marginal branches, diagonal branches and posterior descending right coronary artery may be occasionally involved.

Technological advances in radiological techniques have enabled better diagnosis of myocardial bridges especially coronary angiography and coronary computed tomographic angiography (CCTA).

During a routine angiography by means of CCTA in a 60-year-old male patient with arrhythmia, a case of $M B$ was found in two segments of the posterior interventricular artery and a small segment of the right coronary artery.

Although most cases of myocardial bridges are asymptomatic, knowledge of its pathophysiology is of great clinical importance as some cases of MBs have been associated with acute coronary syndromes, ischaemia, arrhythmias and even sudden death. (Folia Morphol 2020; 79, 2: 411-414)

Key words: myocardial bridges, intramyocardial coronary artery, right coronary artery, posterior interventricular artery, angiography, coronary computed tomographic angiography (CCTA)

\section{INTRODUCTION}

The heart is supplied by branches of the right and left coronary arteries [20] and because these vessels and their major branches course along the surface of the heart, they are called epicardial coronary arteries [21]. Occasionally, however, a portion of the vessels may be embedded within the myocardium, and thus, the artery is said to have "tunnelled" under a "bridge" of myocardium $[3,4,21]$. This anatomical variation, which is a congenital anomaly [1], is called a myocardial bridge. In other words, in myocardial bridging, as the coronary vessel travels along the epicardial surface of the heart, it then dips under the muscle tissue of the heart and then reappears again on the heart's surface [2].

The first anatomic description of myocardial bridges was made by Reyman in $1737[1,9]$ and then by Black in 1805. This was then followed by the first post-mortem examination by Geiringer in 1951 [6] and the first radiological description by Portsmann and Iwig in $1960[1,10]$.

The clinical significance of myocardial bridges is an area of controversy among researchers, with some investigators suggesting they are benign $[1,13$, $21]$ or asymptomatic $[12,17]$ and others reporting complications associated with myocardial bridges $[3,4,7,21]$. Some of the clinical conditions associated with myocardial bridges include arrhythmias, ischaemia and acute coronary syndromes and even sudden death $[1,2,4,21,22]$.

The role of myocardial bridges in atherosclerosis is another point of controversy as Soran et al. [21] and Loukas et al. [11] suggest that they might have "protective effects" and Ishii et al. [8], Lee and Chen [10], and Zeina et al. [22] described the bridged segment

Address for correspondence: Dr. M. Tiryakioğlu, Department of Anatomy, Faculty of Medicine, Near East University, Nicosia, Cyprus, e-mail: mehtap.tiryakioglu@neu.edu.tr 
of the artery to be spared from atherosclerosis, even though the segment proximal to the bridged segment showed atherosclerotic changes. Schar [19] is of the opinion that the bridged segment is not protected from atherosclerotic changes.

This is a case report of myocardial bridging in 3 segments of the right coronary artery (RCA) as follows; a small segment of the terminal branch of the RCA and 2 segments of the posterior interventricular branch; in a 60-year-old male patient with arrhythmia.

\section{CASE REPORT}

This is a case report of a 60-year-old male patient who presented as a case of arrhythmia and routine angiography showed a case of myocardial bridging in 3 segments of the RCA.

The left coronary artery, after taking its origin from the left aortic sinus, gives off the anterior interventricular branch (left anterior descending coronary artery [LAD]) and circumflex branch, which showed normal calibre.

After taking its origin from the right aortic sinus, the RCA passes in front of the pulmonary trunk giving off branches before passing in the coronary sulcus to the posterior aspect of the heart. Here, it gave off a large posterior interventricular branch which showed a small myocardial bridge immediately after its origin. After coursing on the surface of the heart, the posterior interventricular artery enters the interventricular groove and then dips significantly into the myocardium before reappearing on the surface. The terminal branch of the RCA continues still continues in the coronary sulcus, and presents a small myocardial bridge close to where the posterior interventricular branch is given off.

The bridged segment showed systolic compression on the coronary computed tomographic angiography (CCTA). No evidence of atherosclerotic changes in the bridged segment or proximal to it. Even though, there was significant bridging in the posterior interventricular branch of the RCA, the radiology report for the CCTA could not establish the myocardial bridging as the cause of the arrhythmia. The arrhythmia only occurred transiently and there was no repeat episode since then. All other clinical assessments of the patient were essentially normal (Fig. 1).

\section{DISCUSSION}

Coronary arteries and their branches normally course in the epicardium; however, in some areas,

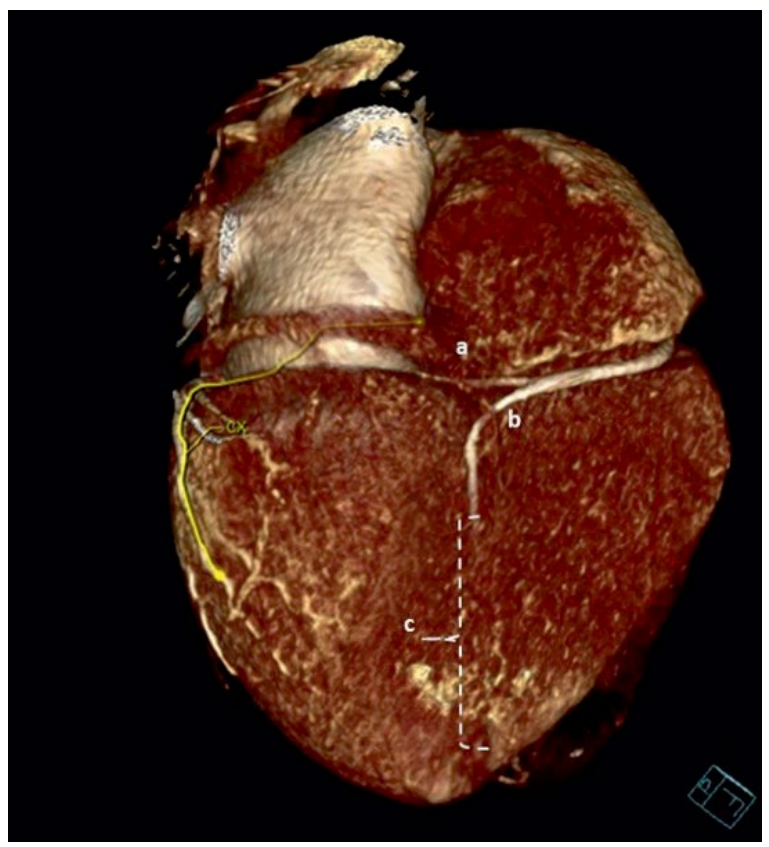

Figure 1. Postero-inferior view. Coronary computed tomographic angiography volume rendered image showing a small tissue crossing the terminal branch of the right coronary artery (a) and the initial segment of the posterior interventricular artery (b); and a significant myocardial bridging of the posterior interventricular artery (c).

a segment of the artery or its branches are partly covered by myocardium, a condition called myocardial bridging [13]. Myocardial bridges are mostly found on the middle segment of the $\operatorname{LAD}[9,10,13]$, although they can occur in any epicardial coronary artery, such as diagonal branches, posterior descending RCA or marginal branches of the circumflex artery [2]. The current case report showed a significant bridging of the middle segment of the posterior interventricular branch of the RCA. Corban et al. [4] reported from $67 \%$ to $98 \%$ of cases of myocardial bridges occurring in the LAD while Möhlenkamp et al. [12] reported incidences of $18 \%$ and $40 \%$ for diagonal and marginal branches, respectively. Polacek [15] recorded a frequency of $70 \%$ in LAD, $40 \%$ in left circumflex artery and $36 \%$ in the RCA. Nguyen et al. [14] described a rare case of substantial myocardial bridging in the $2^{\text {nd }}$ posterolateral branch and some bridging in the $1^{\text {st }}$ posterolateral branch of the RCA.

Myocardial bridges can be classified as superficial or deep $[1,4,5,7,10,17]$ on the basis of its depth in the myocardium; and there could be multiple bridged segments in one vessel [17], as is the case in the current case study which presents 2 bridged segments in the posterior interventricular artery. Superficial 
myocardial bridges are commoner $[1,5,7,10]$ than the deep bridges with an incidence of $75 \%$ and $25 \%$, respectively [5]. Riezzo et at. [16] reported a superficial bridging in the descending branch of the RCA about $1 \mathrm{~cm}$ from its origin.

Gould et al. [7] categorised myocardial bridges as superficial being between 1 to $2 \mathrm{~mm}$ deep and deep bridges greater than $2 \mathrm{~mm}$ deep in the myocardium. Another classification of myocardial bridges is based on the orientation of the myocardial fibres over the bridged segment. Loukas et al. [11] and Ferreira et al. [5] described superficial myocardial bridges as myocardial fibres crossing the LAD transversely at an acute angle or perpendicularly and deep bridges as fibres crossing the LAD and then surrounding it.

Another classification has been described by Corban et al. [4] as myocardial bridges being complete when the LAD is completely covered by myocardial tissue, and incomplete when the bridged segment is only covered by a thin layer of connective tissue and fatty tissue. In the current case report, the bridged segments could be classified as 2 incomplete segments in the terminal branch of the RCA and the $1^{\text {st }}$ part of the posterior interventricular branch, as these segments were only covered by a thin layer of connective tissue; and a complete bridged segment of the remaining part of the posterior interventricular branch.

Nasr [13] studied 60 adult cadaveric human hearts and reported $13.8 \%$ cases of bridging in the posterior interventricular artery. The current case report also showed significant bridging of the posterior interventricular artery. Kosiński and Grzybiak [9] dissected 100 adult human hearts and recorded only $4 \%$ of myocardial bridging in the posterior interventricular branch.

The prevalence of myocardial bridges vary between autopsy studies and diagnostic methods with some researchers reporting frequencies of up to $15-85 \%$ on autopsy and $0.5-2.5 \%$ demonstrated radiographically $[5,12,22]$. Some researchers report estimated frequencies of $1.5-16 \%$ in coronary angiography and $80 \%$ for autopsy cases $[4,6,18]$. Although coronary angiography is the most common diagnostic technique, computed tomography angiography has shown higher detection rates of myocardial bridges [10].

\section{CONCLUSIONS}

Myocardial bridges are congenital anomalies involving mostly the LAD although any epicardial vessel can be involved. Due to the high incidence of myocardial bridges, detailed knowledge of the pathophysiology is of great clinical significance and will go a long way in improving patient care.

\section{REFERENCES}

1. Alegria JR, Herrmann J, Holmes DR, et al. Myocardial bridging. Eur Heart J. 2005; 26(12): 1159-1168, doi: 10.1093/ eurheartj/ehi203, indexed in Pubmed: 15764618.

2. Bourassa MG, Butnaru A, Lespérance J, et al. Symptomatic myocardial bridges: overview of ischemic mechanisms and current diagnostic and treatment strategies. J Am Coll Cardiol. 2003; 41(3): 351-359, doi: 10.1016/s07351097(02)02768-7, indexed in Pubmed: 12575960.

3. Bruschke AVG, Veltman CE, de Graaf MA, et al. Myocardial bridging: what have we learned in the past and will new diagnostic modalities provide new insights? Neth Heart J. 2013; 21(1): 6-13, doi: 10.1007/s12471-012-0355-x, indexed in Pubmed: 23197048.

4. Corban MT, Hung OY, Eshtehardi P, et al. Myocardial bridging: contemporary understanding of pathophysiology with implications for diagnostic and therapeutic strategies. J Am Coll Cardiol. 2014; 63(22): 2346-2355, doi: 10.1016/j. jacc.2014.01.049, indexed in Pubmed: 24583304.

5. Ferreira AG, Trotter SE, König B, et al. Myocardial bridges: morphological and functional aspects. Br Heart J. 1991; 66(5): 364-367, doi: 10.1136/hrt.66.5.364, indexed in Pubmed: 1747296.

6. Geiringer E. The mural coronary. Am Heart J. 1951; 41(3): 359-368, doi: 10.1016/0002-8703(51)90036-1.

7. Gould KL, Johnson NP. Myocardial bridges: lessons in clinical coronary pathophysiology. JACC Cardiovasc Imaging. 2015; 8(6): 705-709, doi: 10.1016/j.jcmg.2015.02.013, indexed in Pubmed: 26068287.

8. Ishii T, Asuwa N, Masuda S, et al. The effects of a myocardial bridge on coronary atherosclerosis and ischaemia. J Pathol. 1998; 185(1): 4-9, doi: 10.1002/(SICI)10969896(199805)185:1<4::AID-PATH50>3.0.CO;2-3, indexed in Pubmed: 9713353.

9. Kosiński A, Grzybiak M. Myocardial bridges in the human heart: morphological aspects. Folia Morphol. 2001; 60(1): 65-68, indexed in Pubmed: 11234701.

10. Lee MS, Chen $\mathrm{CH}$. Myocardial bridging: an up-to-date review. J Invasive Cardiol. 2015; 27(11): 521-528, indexed in Pubmed: 25999138.

11. Loukas M, Curry B, Bowers M, et al. The relationship of myocardial bridges to coronary artery dominance in the adult human heart. J Anat. 2006; 209(1): 43-50, doi: 10.1111/j.14697580.2006.00590.x, indexed in Pubmed: 16822268.

12. Möhlenkamp S, Hort W, Ge J, et al. Update on myocardial bridging. Circulation. 2002; 106(20): 2616-2622, doi: 10.1161/01.cir.0000038420.14867.7a, indexed in Pubmed: 12427660.

13. Nasr AY. Myocardial bridge and coronary arteries: morphological study and clinical significance. Folia Morphol. 2014; 73(2): 169-182, doi: 10.5603/FM.2014.0025, indexed in Pubmed: 24902096.

14. Nguyen TH, Burnside PR, Dieter RS, et al. Right coronary artery distribution of myocardial bridging: an unusual case 
presenting with ST-elevation myocardial infarction. Tex Heart Inst J. 2007; 34(4): 489-491, indexed in Pubmed: 18172538.

15. Polacek P. Relation of myocardial bridges and loops on the coronary arteries to coronary occulsions. Am Heart J. 1961; 61: 44-52, doi: 10.1016/0002-8703(61)90515-4, indexed in Pubmed: 13736661.

16. Riezzo I, Monciotti F, Pomara C, et al. Myocardial bridging of the right coronary artery and emotional stress: a fatal link? Int J Cardiol. 2007; 115(3): e99-101, doi: 10.1016/j. ijcard.2006.07.060, indexed in Pubmed: 17052778.

17. Rogers IS, Tremmel JA, Schnittger I. Myocardial bridges: Overview of diagnosis and management. Congenit Heart Dis. 2017; 12(5): 619-623, doi: 10.1111/chd.12499, indexed in Pubmed: 28675696.

18. Rossi L, Dander B, Nidasio GP, et al. Myocardial bridges and ischemic heart disease. Eur Heart J. 1980; 1(4): 239-245, doi: 10.1093/oxfordjournals.eurheartj.a061125, indexed in Pubmed: 7274234.

19. Schar B. Myocardial bridging: Symptoms of coronary disease that sometimes is not (German). Schweiz Rundsch Med Prax. 2000; 67: 206-209.

20. Sinnatamby CS. Last's Anatomy: Regional and Applied. 12th Ed. Churchill Livingstone Elsevier 2011: 203-205.

21. Soran O, Pamir G, Erol C, et al. The incidence and significance of myocardial bridge in a prospectively defined population of patients undergoing coronary angiography for chest pain. Tokai J Exp Clin Med. 2000; 25(2): 57-60, indexed in Pubmed: 11127508.

22. Zeina $A R$, Odeh $M$, Blinder J, et al. Myocardial bridge: evaluation on MDCT. AJR Am J Roentgenol. 2007; 188(4): 1069-1073, doi: 10.2214/ajr.06.0714, indexed in Pubmed: 17377049. 